\title{
Impacts of river alteration for flood control on freshwater turtle populations
}

\author{
Hayato Usuda $\cdot$ Takae Morita $\cdot$ Masami Hasegawa
}

Received: 22 August 2009/Revised: 29 September 2010/Accepted: 8 October 2010/Published online: 25 November 2010

(C) The Author(s) 2010. This article is published with open access at Springerlink.com

\begin{abstract}
The impacts of artificial river alteration for flood control on the dynamics of freshwater turtle populations were studied in small urban and rural river systems in northwestern Chiba Prefecture, Japan, from 2003 to 2006. The population density of the Reeve's turtle, Chinemys reevesii, decreased markedly, from 279 turtles $\mathrm{km}^{-1}$ in 2003 to 43 turtles $\mathrm{km}^{-1}$ in 2006 in association with the artificial river alteration practices implemented by 2006 . Low turtle population densities in other river sections where flood control measures have already been implemented suggest slow population recovery. River alteration practices also altered the age structures, sex ratios, and demographic characteristics of the turtle populations, although the exact consequences for population viability have not yet been determined. Because the turtles select concave submerged riverbanks or bottoms with slow or no current velocity, increased current velocity in the altered river section make the entire riverbank and bottom unsuitable for hibernation. Overall, river alteration for flood control during the winter season when turtles are inactive due to low water temperature negatively impacted freshwater turtle populations.
\end{abstract}

Keywords River alteration - Flood control - Freshwater turtles · Population decline $\cdot$ Hibernation sites

\footnotetext{
H. Usuda $(\bowtie) \cdot$ M. Hasegawa

Department of Biology, Faculty of Science, Toho University,

2-2-1 Miyama, Funabashi, Chiba 274-8510, Japan

e-mail: bsbird@attglobal.net

T. Morita

Citizens School of Shiroi Environmental Conservation

and Education, Shiroi, Japan
}

\section{Introduction}

Artificial riverbank alteration for flood- and bank-erosion control measures, such as riprapping, removal of vegetation, and deepening of river bottoms, are regarded as primary causes of rapid and extensive declines in many freshwater fishes, invertebrates, and mossy vegetation (Miura and Uchida 2004; Nakano and Nakamura 2008; Nagayama et al. 2008; Nakano et al. 2008; Nakamura and Komiyama 2010). Therefore, various conservation countermeasures, such as reclamation of natural watercourses, removal of dams or weirs that interfere with up- and downstream migration, and facilitation of fish movement among rivers and surrounding shallow marshes for spawning and feeding, have been proposed and implemented (e.g., Wang et al. 2002; Pretty et al. 2003; Suren and McMurtrie 2005; Suren et al. 2005; Nakamura et al. 2006; Nakano and Nakamura 2008; Nagayama et al. 2008; Nakano et al. 2008; Nakamura and Komiyama 2010).

Destruction and deterioration of habitats due to conversion of natural wetlands for agricultural and industrial uses, and lake and riverbank alterations for flood and erosion controls, are recognized as threats to the world's freshwater turtle populations (Dodd 1990; Bodie 2001; Saunders et al. 2002; Spinks et al. 2003). In Japan, turtles living in river systems at the urban-rural interface are threatened by ex situ flood control of midstream areas because expanding housing and urban developments in upstream areas and the resulting increase in surface runoff jointly cause flooding in downstream rural and urban landscapes (Ando and Takahashi 1992, 1997). Especially in areas surrounding Tokyo and other large Japanese cities, rapid urbanization of upstream landscapes has caused river alterations for flood control in many rural areas. Nevertheless, no field studies have quantitatively demonstrated 
the impacts of artificial river alteration on freshwater turtle populations. Therefore, quantitatively documenting the actual threats to freshwater turtle populations is urgently needed in Japan, as well as in other parts of the world.

The goal of this study was to document declines in turtle populations in Japanese urban and rural river systems and to discuss possible causes for the population decline. Our research began in the summer of 2003 as part of an environmental education program for local elementary school children in the city of Shiroi, northwestern Chiba Prefecture, Japan, where the study river is located (Fig. 1). Initially, we captured as many freshwater turtles as possible using baited traps to reveal the hidden abundance and diversity of freshwater turtles in a rural river. We were later notified by officials of the local urban development agency that the river would be altered for flood control in the winter of 2003-2004.

Because we did not have enough time to immediately implement effective conservation strategies to rescue turtle populations or to propose alternatives to the planned river alterations, we decided to monitor the consequences of the

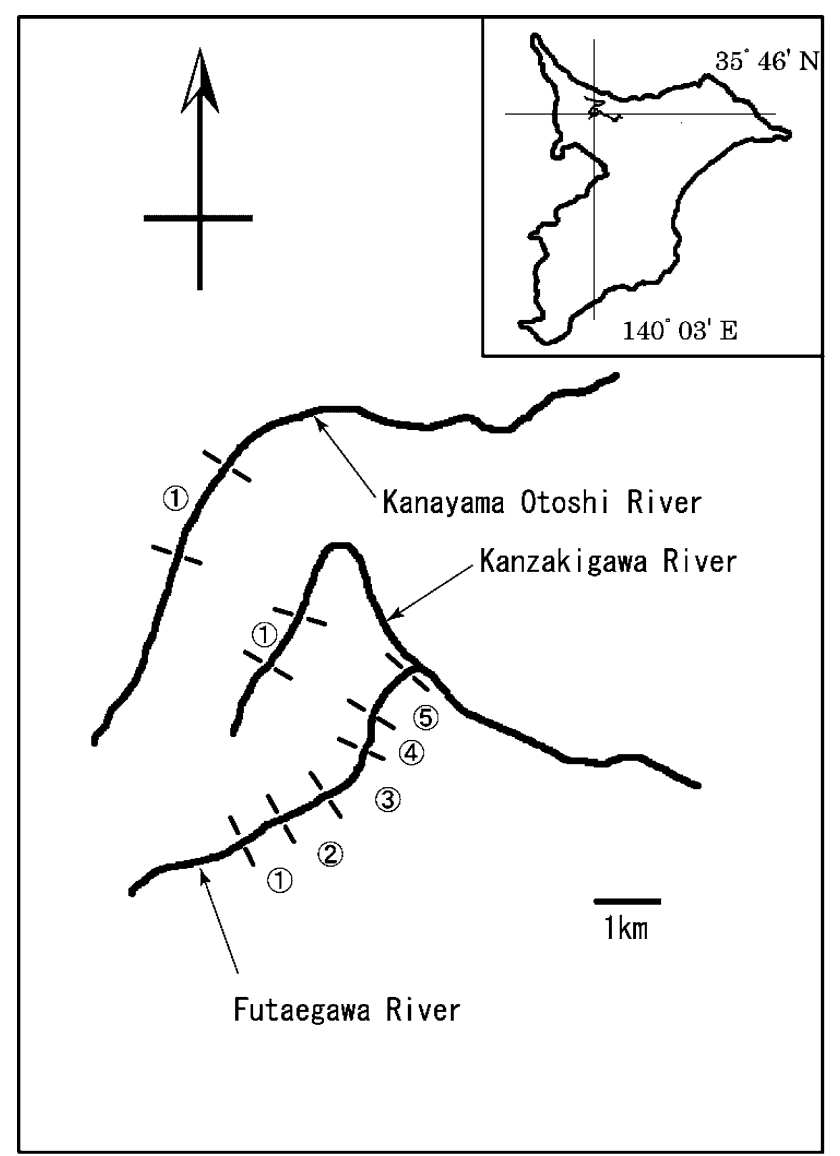

Fig. 1 Riverine systems of the Futaegawa River, the Kanzakigawa River, and the Kanayama Otoshi River in the northwestern Chiba prefecture, Japan. Numerals show the locations of the study section in each river system river alteration. We also implemented an urgent public program to rescue wintering turtles just prior to the start of construction in the fall of 2003. Here, we report the results of a 4-year study of turtle populations in the Futaegawa River, which flows in the city of Shiroi.

\section{Materials and methods}

Study area

Turtle populations were studied in the Futaegawa River, a branch of the Kanzakigawa River, which flows into Lake Inba-numa, Chiba Prefecture, Japan $\left(35^{\circ} 46^{\prime} \mathrm{N}, 140^{\circ} 03^{\prime} \mathrm{E}\right.$, $20 \mathrm{~m}$; Fig. 1). Linear length of the Futaegawa River is $6.4 \mathrm{~km}$, and its basin area is 540 ha. Although the headwaters are located in a heavily urbanized region, the Futaegawa River basin includes extensive rural landscapes, such as groves and marsh areas comprising alders (Alnus spp.), the common reed (Phragmites australis), tall goldenrod (Solidago altissima), and rice paddies. In particular, along the banks of the Futaegawa River before the alterations, plants such as willows (Salix spp.), cattails (Typha spp.), and Manchurian wild rice (Zizania latifolia) grew. River alterations caused by deepening and widening the water course and construction of sloping revetment (Fig. 2), were implemented in the lower half of the Futaegawa River from 1999 through 2006, mostly during the winter months from November to March. We divided the entire river course into five sections, each stretching $0.5-1.0 \mathrm{~km}$ in length, based on riverbank and riverbed conditions caused by river alteration practices. We surveyed turtle populations primarily on one of the five sections of the Futaegawa River where alterations had been implemented from 2003 through 2006. To compare turtle populations living under different anthropogenic impacts, we performed additional turtle surveys in the two other river systems: a 1-km stretch of the Kanzakigawa River, where river alteration had been completed by 2000 , and a $1.7-\mathrm{km}$ stretch of the Kanayama Otoshi River, where no recent river alterations have been implemented. Terraced rice paddies surrounded these river stretches. The Kanzakigawa River was surveyed in 2004, and the Kanayama Otoshi River was surveyed from 2005 through 2006.

Methods

Lake (2001) recommended a before-after, controlintervened (M BACI) design when reference sites are not available to quantitatively evaluate the effects of river alterations on biota. However, because we only started to monitor turtle populations just before the commencement of alterations, we compared turtle population densities 

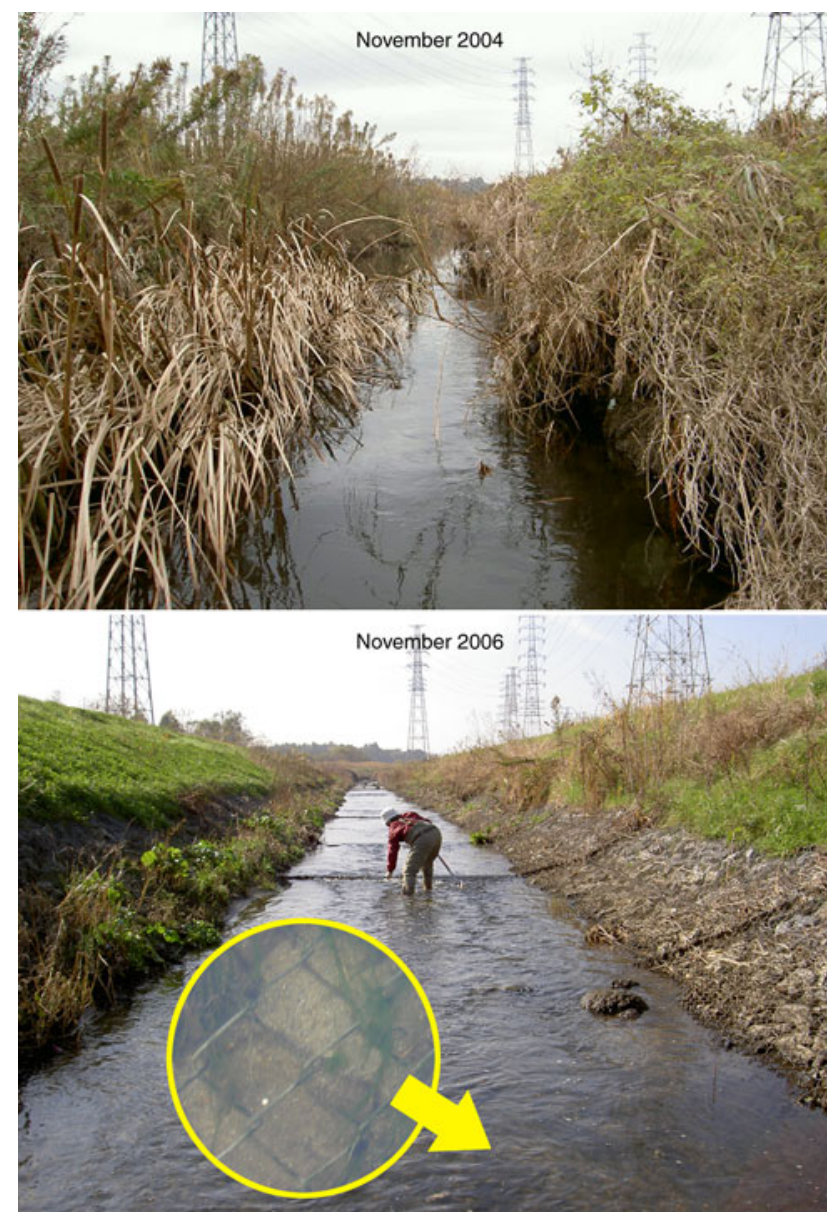

Fig. 2 Futaegawa River in November 2004 (before) and November 2006 (after) alteration practices. Close-up in the circle shows the riverbed covered with the hardware mesh

among five sections of the Futaegawa River, each with a different history of artificial river alteration, and two control sections in the Kanzakigawa and Kanayama Otoshi rivers. Turtles were captured using a baited-trap method (Gibbons 1990) in the open-water bodies from July to September and by hand from November to January while the turtles were hibernating. Captured turtles were uniquely marked with coded numbers by making small holes along the margin of the carapace, and the marking number, species, sex, age, degree of melanism, body length [carapace length (CL); plastron length (PL)], and annuli length on their abdominal lamina were recorded. After being recorded in this manner, turtles were released at the point of capture. The coding system for individual marking followed Cagle (1939), with slight modifications. Sex was distinguished by the relative position of the cloaca; i.e., the female cloaca is located closer to the posterior end of the plastron than that of males. Turtles $<75 \mathrm{~mm}$ in CL were classified as juveniles. Age was determined by counting the number of plastron growth rings (Sexton 1959); turtles whose growth rings could not be identified were placed in the oldest age category. For the Reeve's turtle, Chinemys reevesii, melanic males were classified as mature, and males that were not completely melanic were classified as immature (Yabe 1994). Likewise, females aged $\geq 9$ or those assigned to the old category were classified as mature because the youngest gravid female was 9 years old in C. reevesii (Kosuge, personal communication). Turtle population densities per 1-km stretch were estimated using the mark-recapture method with the Chapman-modified Petersen formula (Chapman 1951; Seber 1970). Because we undertook these surveys over only a few days in each area, the populations were regarded as closed. Field surveys were performed in the Futaegawa, Kanzakigawa, and Kanayama Otoshi rivers in 2003-2006, 2004, and 2005-2006, respectively. We subsequently estimated population densities of respective turtle species by multiplying the estimated total number of turtles irrespective of species by the relative frequency of the species in the Futaegawa River from 2003 through 2006. To demonstrate the effects of river alteration on life history and demographic traits, the proportion of mature turtles, and sex ratios of both mature and immature turtles were examined for $C$. reevesii.

\section{Environmental conditions of the artificially altered river}

To evaluate whether postalteration river environments were still suitable, especially for hibernating turtles, five microhabitat variables (i.e., width, depth, current velocity, substrate, and riverbank and riverbed vegetation) were compared before (2005) and after (2006) alteration for the sections of the Futaegawa River. The surveyed area was divided into a few equally spaced transects, and the numbers of transects measured before and after the alteration were three and two, respectively. These transects covered nearly half the river length in the studied section. In total, ten points were measured along a 100-m section of each transect. River width was measured along a horizontal line $50 \mathrm{~cm}$ above the river surface. Depth and current velocity were measured at all transect lines from the left to right bank at $10-\mathrm{cm}$ intervals. In particular, current velocity was measured by velocity indicator (Limited Private Company: Cosmo Riken, Model: CR-11) longitudinally at three different depths (i.e., surface, middle, and bottom) where the river was deeper than $20 \mathrm{~cm}$. Substrate conditions were recorded as gravel, silt, or mud, and existence of riverbed vegetations was also recorded. During the annual hibernating turtle survey in November from 2003 to 2006, we searched turtles hidden in every possible microhabitat, and the same four microhabitat variables except current velocity (see below) were recorded at the points where the turtles were found. We thus compared microhabitat conditions of the hibernation sites with the general river environment both in the intact or altered sections. For river-current velocity, the largest values along a 
line perpendicular to the direction of flow and extending from hibernation points were recorded.

\section{Results}

Dynamics of turtle populations

Population density (number of turtles per 1-km stretch of river course) of $C$. reevesii decreased significantly, from $279 \pm 98$ turtles $\mathrm{km}^{-1}$ [mean $\pm 95 \%$ confidence interval (CI)] in 2003 to $43 \pm 24$ in 2006 (Fig. 3). Of 180 C. reevesii recaptured for the first time in each river section surveyed in 2003-2006, $141(78.3 \%)$ were recaptured in the same river section, and $39(21.7 \%)$ were found in the sections either upstream or downstream adjacent to the sections of first capture. For turtles that moved to other sections, the mean distance between the initial and recaptured sites was $913 \pm 333 \mathrm{~m}$ [mean \pm standard error $(\mathrm{SE}), n=33$ ], whereas the mean distance between captures within the same sections was $258 \pm 236 \mathrm{~m}$ (mean $\pm \mathrm{SE}, n=138$ ). We failed to accurately record capture points of nine turtles so that data of those turtles was excluded from the analysis.

In the sections where river alterations had already finished before we began our first survey in the Futaegawa and Kanzakigawa rivers, densities of $C$. reevesii were approximately one fifth of those of river sections where the riverbank and riverbed were not altered. Although the population density of $C$. reevesii in the intact section of the Kanayama Otoshi River was as low as $50 \%$ of the density in the

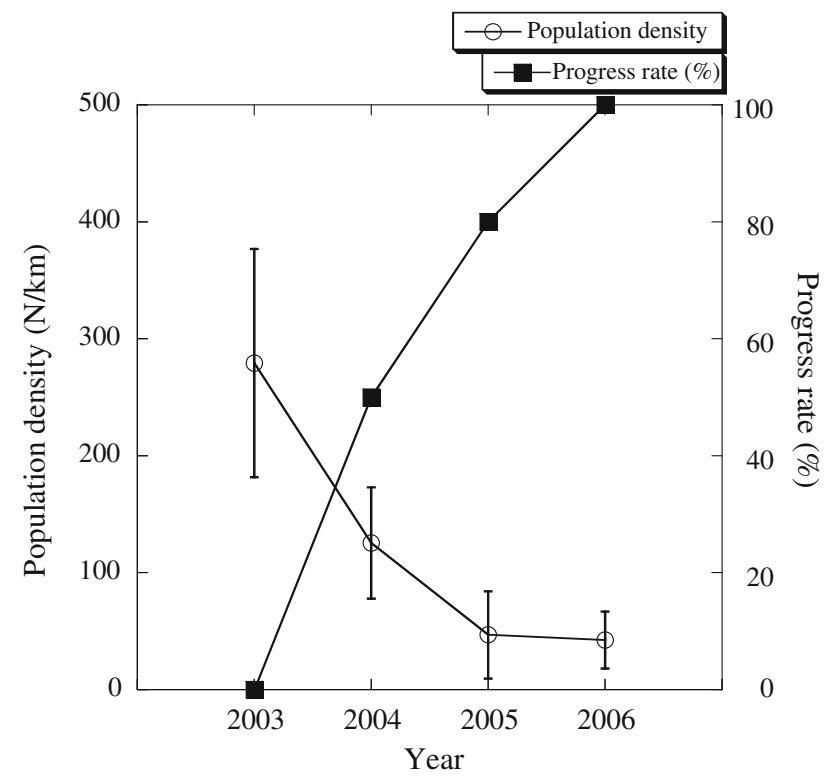

Fig. 3 Changes in estimated population densities of turtles and progress rates of river alteration. Filled squares indicate the progress rates of river alteration. Open circles and error bars show population densities (mean $\pm 95 \%$ confidence intervals)
Futaegawa River in 2003, it was still higher than densities in the altered sections of the Futaegawa and Kanzakigawa rivers. The proportion of immature turtles gradually decreased, from $60.6 \%$ in 2003 to $23.1 \%$ in 2006 (Table 1). The sex ratio of mature turtles was male-biased in 2003 and 2004 but became female-biased in 2005 and 2006 (Table 1). The sex ratio of immature turtles showed a trend similar to mature turtles, as the sex ratio was male-biased from 2003 to 2005 , but only females were captured in 2006 (Table 1). The Kanayama Otoshi population of $C$. reevesii showed little annual change in the proportion of immature turtles, from $57.9 \%$ in 2005 to $64.9 \%$ in 2006 (Table 2). The sex ratio of mature turtles was male-biased both in 2005 and 2006 and female-biased in immature turtles both in 2005 and 2006 (Table 2). Overall, the proportions of immature and male turtles tended to decrease in the Futaegawa River more so than in the Kanayama Otoshi River.

The ratio of native $C$. reevesii to the exotic slider turtle, Trachemys scripta elegans, was nearly 9:1 in every year except 2006, when the proportion of the slider turtle increased slightly (Table 3 ). Mauremys japonica and a hybrid between C. reevesii and M. japonica were captured only in 2003 and 2004 (Table 3). The densities of C. reevesii, M. japonica, and the $C$. reevesii-M. japonica hybrid decreased from 2003 through 2006, whereas those of T. scripta elegans increased from 2005 through 2006 (Fig. 4). However, the native-toexotic species ratio did not differ significantly among years (chi-square test: $\chi^{2}=3.00, d f=3, P>0.05$ ).

Environmental conditions of the artificially altered river

Physical, structural, and biological conditions of the artificially altered section of the Futaegawa River were compared with those before alteration. The average river width increased from

Table 1 Sex ratios of mature and immature turtles in the Futaegawa River from 2003 to 2006

\begin{tabular}{|c|c|c|c|c|c|c|c|c|}
\hline & \multicolumn{4}{|l|}{ Mature } & \multicolumn{4}{|l|}{ Immature } \\
\hline & Male $(\%)$ & $Z$ & $P$ & $n$ & Male $(\%)$ & $Z$ & $P$ & $n$ \\
\hline 2003 & 69.6 & 2.94 & $<0.01$ & 56 & 61.6 & 2.16 & $<0.01$ & 86 \\
\hline 2004 & 59.5 & 1.23 & 0.22 & 42 & 60.0 & 1.41 & 0.16 & 50 \\
\hline 2005 & 39.1 & 1.04 & 0.30 & 23 & 61.9 & 1.09 & 0.28 & 21 \\
\hline 2006 & 40.0 & 0.63 & 0.53 & 10 & 0.0 & - & - & 3 \\
\hline
\end{tabular}

Table 2 Sex ratios of mature and immature turtles in the Kanayama Otoshi River (control section) from 2005 to 2006

\begin{tabular}{|c|c|c|c|c|c|c|c|c|}
\hline & \multicolumn{4}{|l|}{ Mature } & \multicolumn{4}{|l|}{ Immature } \\
\hline & Male $(\%)$ & $Z$ & $P$ & $n$ & Male $(\%)$ & $Z$ & $P$ & $n$ \\
\hline 2005 & 62.5 & 1.00 & 0.32 & 16 & 40.9 & 0.85 & 0.40 & 22 \\
\hline 2006 & 55.0 & 0.63 & 0.53 & 40 & 23.0 & 4.65 & $<0.001$ & 74 \\
\hline
\end{tabular}


Table 3 Annual changes in species compositions of the freshwater turtles

\begin{tabular}{llllll}
\hline Year & C. reevesii $(\%)$ & T. s. elegans $(\%)$ & M. japonica $(\%)$ & Population density $(n / \mathrm{km})$ & Total number captured \\
\hline 2003 & 90.1 & 6.8 & 3.1 & $305 \pm 100$ & 161 \\
2004 & 88.5 & 9.6 & 1.9 & $136 \pm 49$ & 104 \\
2005 & 88.2 & 11.8 & 0 & $53 \pm 23$ & 51 \\
2006 & 82.4 & 17.6 & 0 & $42 \pm 32$ & 17
\end{tabular}

Combined population density of the turtles was estimated irrespective of the species: Chinemys reevesii, Trachemys scripta elegans, and Mauremys japonica. Numbers for $M$. japonica include $C$. reevesii-M. japonica hybrids

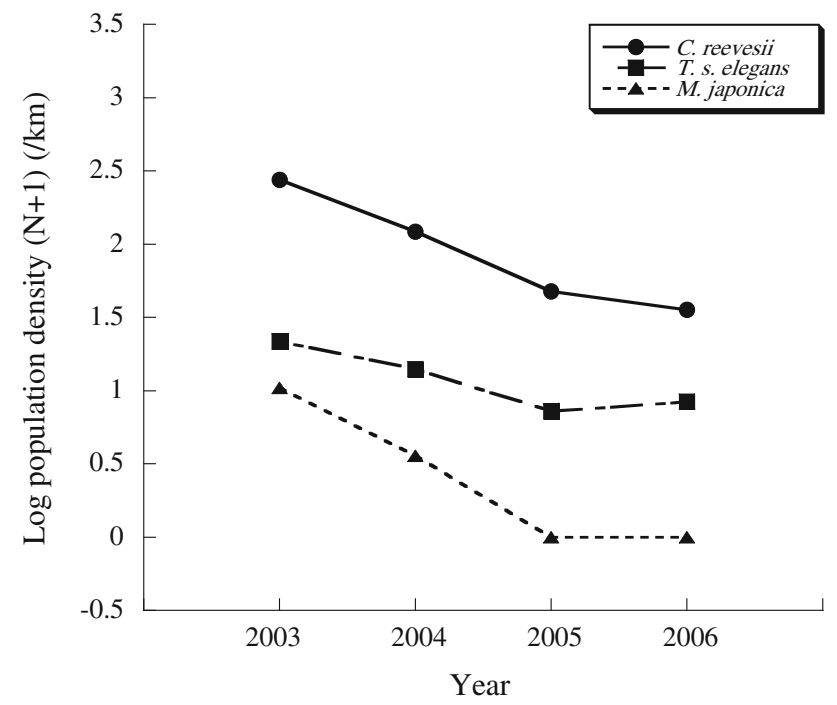

Fig. 4 Population densities of Chinemys reevesii, Trachemys scripta elegans, and Mauremys japonica (including the $C$. reevesii-M. japonica hybrid)

$4.4 \pm 0.5$ to $5.5 \pm 0.4 \mathrm{~m}$ (Mann-Whitney $U$ test: $U=7$, $P<0.001)$, and the average depth decreased from $20.5 \pm 11.2$ to $15.7 \pm 7.6 \mathrm{~cm}$ [analysis of variance (ANOVA) $F=77.7$, $P<0.001)$ when measurements were taken at low water levels. Frequency distributions of river depth indicated that the riverbed became structurally more simple and monotonous (i.e., relatively flat) after alteration (Fig. 5).

The river-current velocity changed markedly with alterations of the riverbank and riverbed. Frequency distributions of current velocity measured along the longitudinal axis of stream flow at the surface, middle, and bottom of the river were skewed; compared with after the alterations, points with slower current $\left(<10 \mathrm{~cm} \mathrm{~s}^{-1}\right)$ were more common than those with rapid current $\left(\geq 10 \mathrm{~cm} \mathrm{~s}^{-1}\right)$ before the alterations (Fig. 5). After alteration, the frequency of rapid currents increased disproportionately (Fig. 5), and the slopes of frequency that regressed on logtransformed velocity (Fig. 6) differed between current frequency profiles before and after the alteration [analysis of covariance (ANCOVA) slopes, $F=6.54, P<0.05$ ).

The riverbed substrate was artificially transformed from a silt and mud bottom to gravel of $5-10 \mathrm{~cm}$ diameter
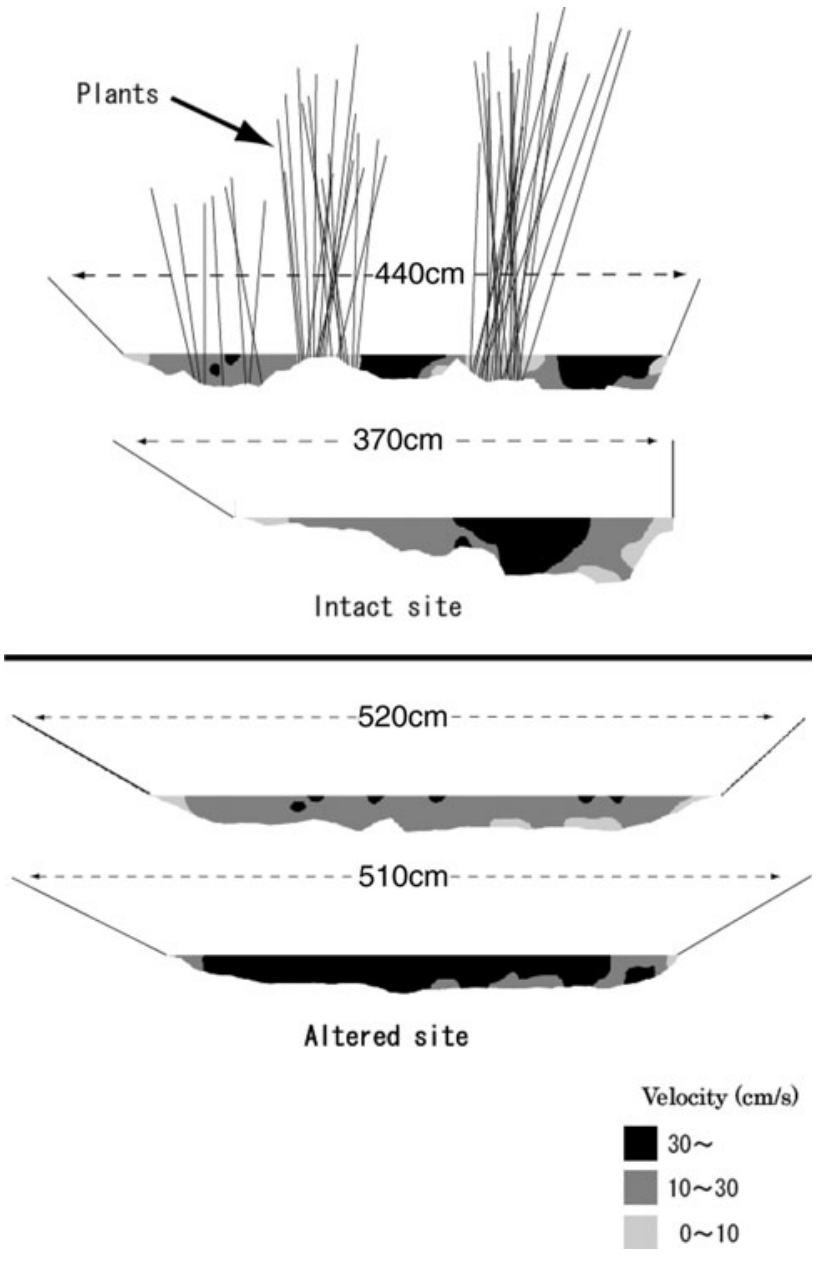

Fig. 5 Cross sections of the river in intact (upper) and altered (lower) sites. Colors indicate different velocities; bars denote vegetation

configured with hardware mesh (Fig. 2). Herbaceous plants naturally growing both on the riverbank and on the riverbed were completely removed during the alteration, with the exception of rapidly growing annual grasses on the riverbank (Fig. 2).

Impacts of river alteration on hibernating turtles

Before the alterations were made in late autumn 2003-2005, hibernating turtle surveys yielded an average of $13.5 \pm 1.7$ 


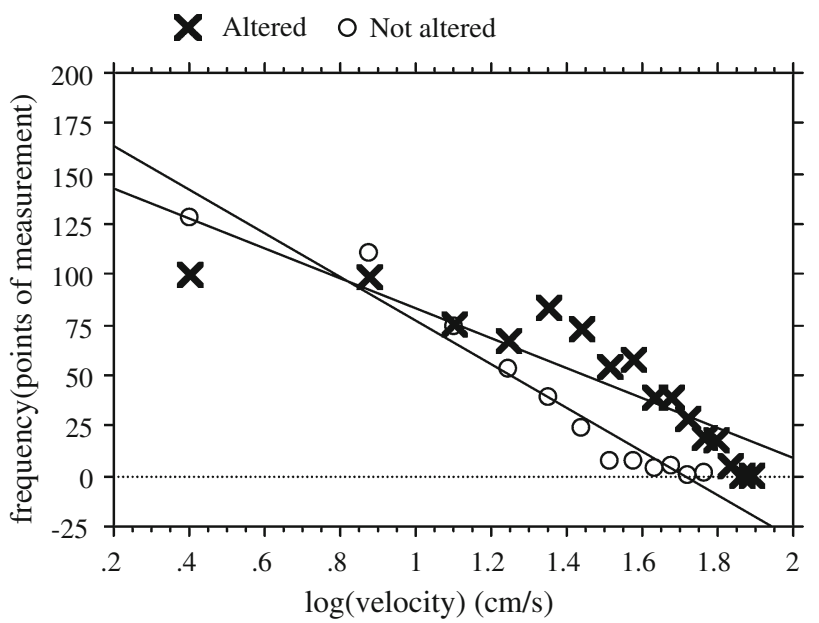

Fig. 6 Current frequency profiles of log-transformed velocity. Circles before alteration, crosses after alteration. Linear regressions yielded a significantly difference (analysis of covariance: slopes, $F=6.54, P<0.05)$

individuals (mean $\pm \mathrm{SD}$ ) per 300-m stretch of the Futaegawa River. After the alteration, only $0.6 \pm 0.8$ turtles were captured in a 300-m stretch of the river. Microhabitats where the turtles were found hibernating consisted of naturally created submerged holes in muddy or silt riverbanks or beneath thick root mats of deciduous willow trees along the shoreline. The depth and current velocity at the hibernation points were $15.9 \pm 0.8 \mathrm{~cm}$ (mean $\pm \mathrm{SE}$ ) and $8.0 \pm$ $0.6 \mathrm{~cm} \mathrm{~s}^{-1}$, respectively. In particular, the value of the current velocity was irrespective of the maximum velocity $\left(38.2 \pm 16.2 \mathrm{~cm} \mathrm{~s}^{-1}\right)$ recorded at the center of the axis perpendicular to the direction of flow. Frequency distributions of the depth and current velocity at hibernation points were biased toward the lower values of intact river environments. Profiles of river depth and current velocity at the river bottom measured along an axis perpendicular to the direction of flow in the intact and altered river were compared with those of sites selected by the turtles for hibernation (Figs. 7, 8). We calculated the percentage of points suitable for hibernation by dividing the number of points where depth and velocity were within the range selected by the hibernating turtles by the total number of points measured. After river alteration, the percentage of points within the range of the depth and velocity favorable for hibernation decreased from $9.5 \%$ to $0 \%$.

\section{Discussion}

We found that freshwater turtle populations are threatened by river alterations in urban and rural landscapes in Japan. Overall, river alteration incurred severe population decline, demographic changes in populations, and deterioration of microhabitat for hibernation. Here, we first examine the

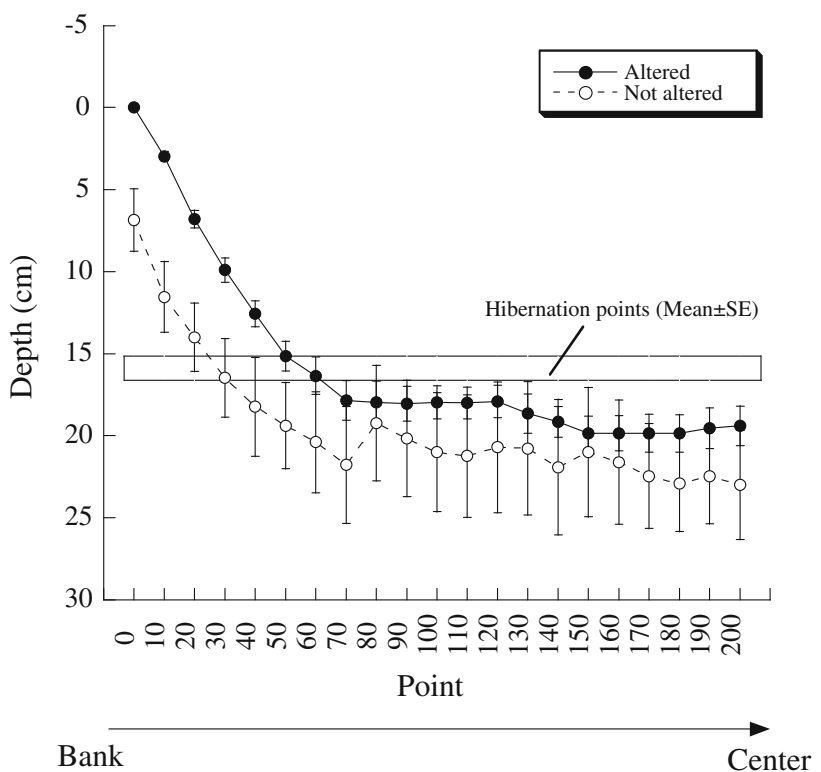

Fig. 7 Depth (mean \pm standard error) along an axis perpendicular to the direction of flow, from the bank to the center of the river, at $10-\mathrm{cm}$ intervals. Open circles before alteration, filled circles after alteration. The depth range of hibernation points is indicated by the horizontal bar

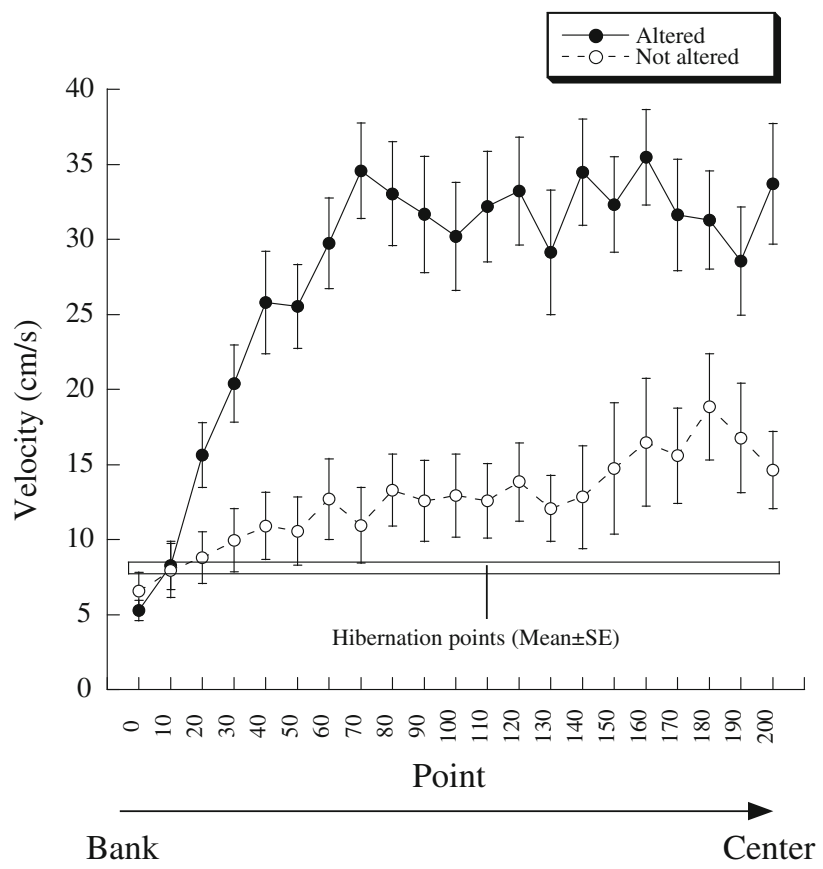

Fig. 8 Velocity (mean \pm standard error) at the river bottom along an axis perpendicular to the direction of flow, from the bank to the center of the river, at $10-\mathrm{cm}$ intervals. Open circles before alteration, filled circles after alteration. The velocity range at hibernation points is indicated by the horizontal bar

possible demographic mechanisms of population decline and then discuss river environmental properties important for ameliorating the negative impacts of river alteration on freshwater turtles. 
River alteration caused severe declines in freshwater turtle populations in the Futaegawa River, probably due to death caused directly by river alteration practices with bulldozers. We tried to reduce the death toll through rescue programs to keep turtles at volunteers' home during the river alteration period. However, the number of turtles rescued was 41 in 2003, and it was only $15 \%$ of the estimated size of turtle populations in the summer of 2003. Therefore, we could not deter population decline despite the fact that turtles kept at volunteers' home actually had a higher survival rate $(80 \%)$ than those that remained on site during the river alteration (Usuda, unpublished data). The considerably lower turtle densities in other rivers that had been altered several years earlier suggest slow population recovery, or depressed carrying capacity of altered river environments due to depletion of food resources, possible disturbance to egg-laying sites, and reduction in suitable basking sites. Reduced population densities after river alteration may be due to turtle avoidance of unfavorable habitats or escape from deteriorated sections of the river. Gibbons (1986) suggested that freshwater turtles are capable of long-distance movement away from unfavorable habitat conditions. However, $78.3 \%$ of recaptures were recorded in the same section of river, whereas turtles recaptured either up- or downstream of the original capture section did not move more than $2 \mathrm{~km}$, with the exception of a few that traveled long distances. Therefore, emigration from unfavorable habitats was an unlikely cause of the sudden population decline associated with these river alteration practices. Demographic mechanisms would also affect population structure. The proportion of mature turtles increased from 2003 to 2006 (Table 1), implying that immature turtles declined much faster than mature turtles, probably due to failure to reproduce or greater mortality among immature turtles. However, reproduction was not completely disrupted, because a few juveniles were captured after river alteration. Changes in age structure and sex ratio would affect future dynamics of the turtle population.

What were the major causes of the decline in turtle populations? Explicit causes would be an implementation of the river alterations in winter, when low water temperatures prevent turtles from avoiding physical disturbance. River alterations are often conducted in the winter for reasons associated with local climate. In Chiba Prefecture, where this study was undertaken, lower precipitation in winter facilitates river alteration. In fact, river alteration is often implemented in seasons with lower precipitation, though there is few published data (e.g., Kaneko et al. 2004). However, to conserve turtle populations, conducting river alterations in winter must be avoided. Furthermore, both meteorological and biological factors must be taken into consideration when determining the timing of river alterations. Changes to the river environment caused by these alterations also impose pressure on native turtle populations. In this study, we showed the differences in the river environment before and after the alteration (Fig. 5). The alterations caused the river to become wider, shallower, faster, and the riverbed more homogeneous. The extent of vegetation was reduced by the alterations. The altered sites are not suitable for hibernation because current velocity is too high. Current velocities at hibernation sites were significantly lower than those at the center of the river, so the altered sites, which had current velocities higher than at intact sites, would not be suitable for hibernation. We captured few hibernating turtles in altered sites. Vegetation on the riverbank and in shallow portions of the riverbed is utilized for hibernation and basking or resting sites, but altered sites had no vegetation. Because turtles hide in the stream bed during hibernation, soft substrates such as mud or silt are essential to provide suitable overwintering sites. Altered sites no longer provided suitable sites for hibernation because the entire river bed was covered with gravel configured by hardware mesh (Fig. 2).

We here make two suggestions to accommodate turtle conservation in future river alteration practices. First, river alteration should not be implemented in winter so as not to harm existing turtle populations. Second, areas with the appropriate physical conditions, especially current velocity, should be created or left intact to maintain suitable turtle habitat. Bunn and Arthington (2002) indicated that longitudinal and lateral river connectivity is essential to maintain the biological viability of many riverine species. Realizing their suggestion would enable not only preserve suitable microhabitats for hibernation but would also sustain the freshwater turtle carrying capacity of the river environment.

Acknowledgments We thank the members of the Geographical Ecology Laboratory for discussions and help with the field survey, and members of the Citizens School of Shiroi Environmental Conservation and Education (NPO) for assisting in the field survey. Special thanks are due to Y. Kosuge and R. Kobayashi for their guidance, advice, and help with the field study.

Open Access This article is distributed under the terms of the Creative Commons Attribution Noncommercial License which permits any noncommercial use, distribution, and reproduction in any medium, provided the original author(s) and source are credited.

\section{References}

Ando Y, Takahashi Y (1992) Historical review of urban flood characteristics for small river basins in Tokyo. Mem Fac Eng Tokyo Metrop Univ 42:4619-4625

Ando Y, Takahashi Y (1997) Recent flood control measures for urban rivers in Japan: case study of the Kanda River in Tokyo. Water Int 22:245-251

Bodie JR (2001) Stream and riparian management for freshwater turtles. J Environ Manag 62:443-455 
Bunn SE, Arthington AH (2002) Basic principles and ecological consequences of altered flow regimes for aquatic biodiversity. Environ Manag 30:492-507

Cagle FR (1939) A system of marking turtles for future identification. Copeia 1939:170-172

Chapman DG (1951) Some properties of the hypergeometric distribution with applications to zoological censuses. University of California, Berkeley. Publ. Stat 1:131-160

Dodd CK Jr (1990) Effects of habitat fragmentation on a streamdwelling species, the flattened musk turtle Sternotherus depressus. Biol Conserv 54:33-45

Gibbons JW (1986) Movement patterns among turtle populations: applicability to management of the desert tortoise. Herpetologica 42:104-113

Gibbons JW (1990) Turtle studies at SREL: a research perspective. In: Gibbons JW (ed) Life history and ecology of the slider turtle. Smithsonian Institution Press, Washington, DC, pp 19-44

Kaneko K, Okuda S, Ohno K (2004) Influences of river improvement on the river ecosystem of the middle reach of the Miyako River. Soc Environ Sci 17:121-128 (in Japanese)

Lake PS (2001) On the maturing restoration: linking ecological research and restoration. Ecol Manag Restor 2:110-115

Miura E, Uchida S (2004) Problems in the practices of river restoration in Aichi and Gifu prefectures, Honshu, Japan. Aichi Inst Technol 39:77-84 (in Japanese)

Nagayama S, Kawaguchi Y, Nakano D, Nakamura F (2008) Methods for and fish responses to channel remeandering and large wood structure placement in the Shibetsu River Restoration Project in northern Japan. Landsc Ecol Eng 4:69-74

Nakamura F, Komiyama E (2010) A challenge to dam improvement for the protection of both salmon and human livelihood in Shiretoko, Japan's third Natural Heritage Site. Landsc Ecol Eng 6:143-152
Nakamura K, Amano K, Tockner K (2006) River restoration: European perspectives and lessons for Japan. Ecol Civil Eng 8:201-214

Nakano D, Nakamura F (2008) The significance of meandering channel morphology on the diversity and abundance of macroinvertebrates in a lowland river in Japan. Aquat Conserv Mar Freshw Ecosyst 18:780-798

Nakano D, Nagayama S, Kawaguchi Y, Nakamura F (2008) River restoration for macroinvertebrate communities in lowland rivers: insight from restorations of the Shibetsu River, north Japan. Landsc Ecol Eng 4:63-68

Pretty JL, Harrison SSC, Shepherd DJ, Smith C, Hildrew AG, Hey RD (2003) River rehabilitation and fish populations: assessing the benefit of instream structures. J Appl Ecol 40:251-265

Saunders DL, Meeuwig JJ, Vincent ACJ (2002) Freshwater protected areas: strategies for conservation. Conserv Biol 16:30-41

Seber GAF (1970) The effects of trap response on tag recapture estimates. Biometrika 26:12-22

Sexton OJ (1959) A method of estimating the age of painted turtles for use in demographic studies. Ecology 40:716-718

Spinks PQ, Pauly GB, Crayon JJ, Shaffer HB (2003) Survival of the western pond turtle (Emys marmorata) in an urban California environment. Biol Conserv 113:257-267

Suren AM, McMurtrie S (2005) Assessing the effectiveness of enhancement activities in urban streams: responses of invertebrate communities. River Res Appl 21:439-453

Suren AM, Riis T, Biggs BJF, McMurtrie S, Barker R (2005) Assessing the effectiveness of enhancement activities in urban streams: habitat responses. River Res Appl 21:381-401

Wang L, Lyons J, Kanehl P (2002) Effects of watershed best management practices on habitat and fish in Wisconsin streams. J Am Water Resour Assoc 38:663-680

Yabe T (1994) Population structure and male melanism in the Reeves' turtle, Chinemys reevesii. Jpn J Herpetol 15:131-137 